An Anti-Tuberculosis Association ean be even more effective by insisting on the enforeement of local or municipal laws, such, for instance, as those requiring physicians to register all cases of tuberculosis, obliging cities to build. and maintain tubereulosis hospitals and dispensaries, and forbidaling spitting in public. places. It is also possible for an Association to do good work along the line of mrging ample appropriations for the maintenance of munieipal hospitals, dispensaries, murses, open air schools and the Ilealth l)epartmont.

\title{
CoijplitTHON.
}

One of the most important things for an Association to cultivate is hearty coijperation with the health authorities, reliof agencies, and the various eivie bodies. It should always bear in mind that each of these anencies is necessarily looking at the tubereulosis problem from a different point of view, which, while it may not. coincide with the point of view of the Association, is nevertheless worthy of the most thoughtful consideration. 'Toleration is a valuable characteristic and the Association that possessess it will find it comparatively easy to coöperate with ofleres.

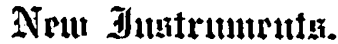

\section{HOME-MADE PROLBS.}

By limnest loyex Young, M.I), Boston,

dmintor lisiting Physiciun for Miscases of Homen. Boston. (rity Mlospital: Assistunt in Gyncolog!n!, llareard bedical Nohool.

Probes are alwals hereming lost or mislaid, and it is often impossible to procure one of suitable size, length or pliability for special axplorations, or in some emergeney.

If of a size pliable anongh to follow a delirate sinus, the tips are apt to be so small as " to cengage in any slight irregularity of the passsage, and so mislead as to its extent. Further'more, the material is often so stiff that the probe refuses to follow the tortuons course in frialle tissue, and a false passage is the pesult.

In an cmereneng a very serviecable probe for small simuses may be made hy tipping a stramel of silkworm gut with a drop of pallattin, of by wapping one end with a wisp of eolton and then dipping one or twiee in collodion. When pillealfin is used, the and of the gut should be secorehed in the flame, which ronghens it and makes the paraffin bead secure. Metal prohes are maturally more satisfactory, and the writer having found it mecessalry, in severnl cases, to employ probes ol ereater length and flexibility

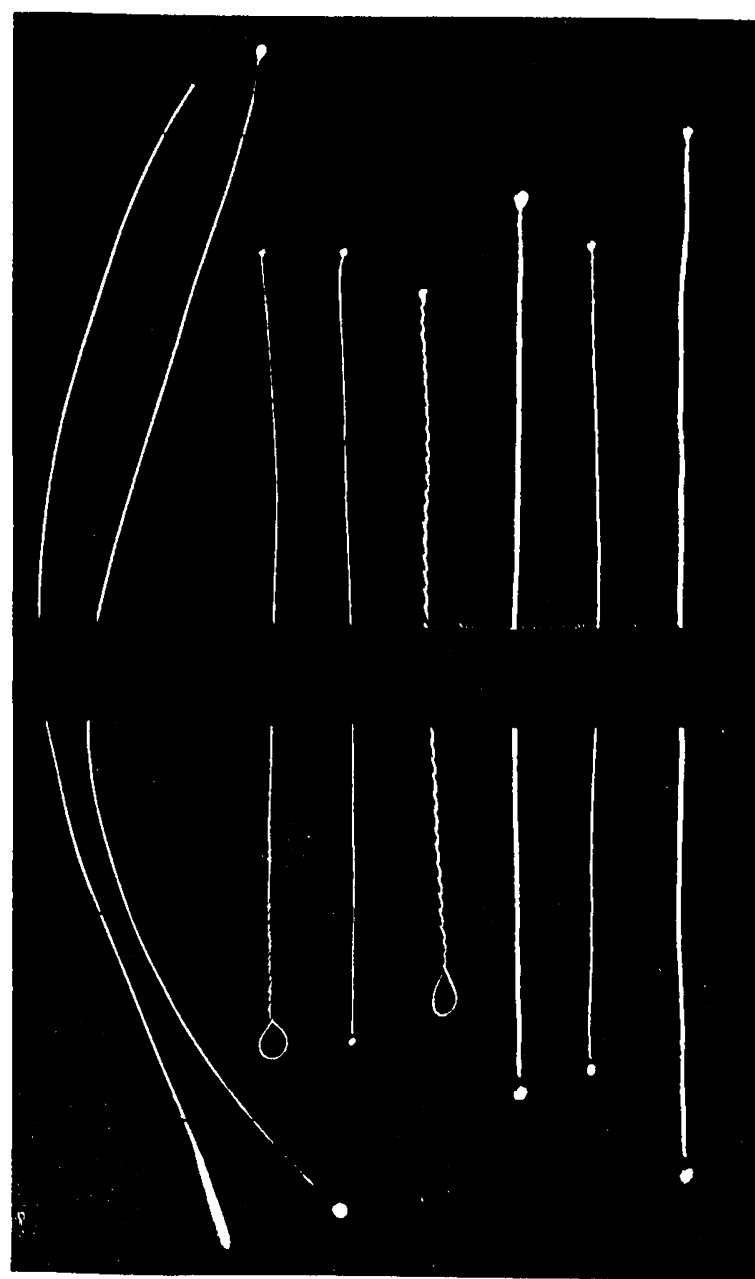

$$
\begin{aligned}
& \text { Silli worm ant tipled witl cotton. } \\
& \text { 2. Simse tipmed with pratatth. } \\
& \text { 3. Silver wire with berax beald. } \\
& \text { 4. (inper wire probs. } \\
& \text { 5) :ll:1 ti. Silvel wire. }
\end{aligned}
$$

than rould be bought, has manulatetured them for his own use by a method so simple, that it may be generally useful. In the making. it is possible to vary the si\%e of the beaded tip, areording to the caliber of the sinus, so that a very flexible fine probe may be armed with a tip nearly as larege as those on the haty probes sold by the instrument makers, thus providing a flexible probe and at the same time minimizing the damere of the tip engaging or

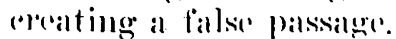

Silver or copper wires of suitable size. are most. uselul althongh silver is the better: as the smaller silver wires are asily fusin in the common allohol ftame, while larerer copper

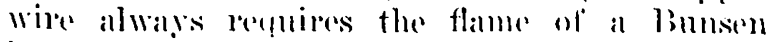
hurner. The eopper wire also oxidizes and may bereme rough, while the silver wire eomes from the flame lnight and ready for use. IIow-

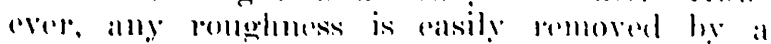

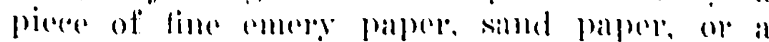
whetstome. while the romelumess of the eoppere maly he obviated by dippine the hot wire in 
powdered borax, and again heating in the flame. The borax bead of the chemical laboratory also makes an excellent tip.

Under all circumstances, a Bunsen flame is preferable, as the greater heat gives a smoother bead, but for smaller wire the alcohol flame is sufficient.

Larger probes may be made by twisting together strands of smaller wire, and then forming a bead on one extremity. A loop may also be left on the folded end for the insertion of a strand of silk or other material which it may be desired to introduce into the sinus, or as a guide to indicate the direction of the passage.

Probes made in this manner are also useful in "stirring up" indolent granulations; the twists of the wire acting as a mild curet when pushed back and forth.

The wire should be held upright in the flame until a sufficient bead has collected. $A$ few trials enable one to estimate the size of bead which a given wire will hold, as if allowed to become too large, the melted metal will drop from the wire.

The photograph shows various probes made by the methods described.

\section{Reparta af Sariztipr.}

\section{THE COLLEGE OF PHYSICIANS OF PHILA- DELPHIA.}

Meeting of Wednesday, March 4, 1914 at $8 \mathrm{P}$. M. The President, Dr. James C. Wilson, in the chair.

THREE CASES OF WIRING WITI ELECTROLYSIS FOR AORTIC ANEURYSM. ONE HERE'TOFORE IN PART REPORTED.

Dr. H. A. Hare: Three additional cases of wiring with electrolysis for aneurysm of the thoracic aorta are reported and a patient exhibited illustrating the beneficial effects of this procedure more than four years after the first operation and more than two years after his second wiring which was resorted to because he had a return of very severe pain and a marked bulging near the site of the original sac. The great gain is arrest of the lesion and relief of pain.

To my conclusions in an article published by me in the Journal of the American Medical Association of April 13, 1912, I would now add that after having performed this operation twenty-five times $I$ can see no reason for changing the views then expressed. I desire, however, to emphasize onco more the fact that only especially prepared wire can be used and that silver wire, because it does not coil, is an unsuitable agent.

\section{DISCUSSION.}

Dr. Groner W. Norris: I should like to ask Dr. Hare whether the wire introduced into an ancurysm is ever absorbed? I have an impression that in one case of which I have knowledge no wire was found at autopsy.

Dr. Thomas McCrae: I agree with Dr. Hare regarding the absence of danger in wiring, if properly done. Regarding the curious course taken by the wire, I have a specimen in which two loops passed through the aortic orifice and down to the lower end of the ventricle. I have seen one case of anatomical cure of abdominal ancurysm after wiring. The patient died from a second aneurysm which was also wired but without the result of the first occasion. I would ask J). Hare whether he has any theory upon the relief of pain by the wiring and electrolysis. The question is certainly not one of coagulation.

Dr. James Tyson: On March 27, 1911, I presented to the Section on Medicine of the College an aneurysm which had been twice wired in my wards at the University Hospital, wherein, too, one piece of wire had passed through the aortic orifice down into the apex of the ventricle by two loops.

Dr. RoBrelet N. WiLt,Son, JR.: Dr. Hare has encouraged me to mention the unfavorable results of a series of wirings done by us at the Philadelphia Hospital. Of six large aneurysmal sacs four were thoracic; two, abdominal. Five of the patients died within three days after wiring. In all cases the procedure was carried out practically as outlined by Dr. Hare. All showed marked relief from pain immediately following operation. One of the patients went back to work and lived for several months. Not one was benefited permanently. While there was immediate relief from pain, almost without exception, the wiring seemed active in hastening the end. During fourteen years I have seen many times for a colleague a patient with a large slowly growing aneurysm under the upper picce of the sternum, and who during this entire timo has been living with reasonable comfort.

Dr. Hare, closing: Answering the inquiry whether or not the wire is at times absorbed I would say that it is. I have known of one other case already reported in which at autopsy no wire could be found. I do not know whether, finding a tiny point of the wire protruding, the man had for amusement, pulled it out; or, it had undergone some process of absorption. I am inclined to thing that in some cases the wire may have been partly destroyed by the electrolytic process, particularly, if by any mishap, the negative instead of the positive pole were used. The most notable effect in my series of 25 cases of wiring is the relief of pain. The wire used must have temper so that if handled it will spring into the air. I. do not see how coagulation can fail to occur if there has been no mistake in the use of the poles. I attribute the relief from pain to the sedative influence of the galvanic current (although I have not much confidence in electro-therapcutics), and to the removal of the strain upon the sac by the clotting. In cases unimproved or in which there is recurrence of pain it is often found that there is more than one aneurysm. The question at issue is whether we shall operate, or allow a man to live in pain. Of course there must be care in the sclection of cases. In two eases seen within the last two months operation would have been unjustifiable. In one the sac was filled with a laminated elot. In the other case there was a history of pain and bulging in the third inter- 